\title{
Property Relationship in Organosilanes and Nanotubes filled Polypropylene Hybrid Composites
}

\author{
Alejandra J. Monsiváis-Barrón ${ }^{1}$, Antonio Sánchez-Fernández ${ }^{2 *}$ and Jaime Bonilla-Rios ${ }^{2 *}$ \\ 1 Tecnológico de Monterrey, Av. Eugenio Garza Sada Sur 2501, Tecnológico, 64849 Monterrey, \\ Nuevo León; E-Mails: a00787292@ itesm.mx \\ 2 Tecnológico de Monterrey Av. Eugenio Garza Sada Sur 2501, Tecnológico, 64849 Monterrey, \\ Nuevo León; E-Mails: asanfer@itesm.mx; jbonilla@itesm.mx \\ * Author to whom correspondence should be addressed; E-Mail: jbonilla@itesm.mx; \\ Tel.: +52-81-8158-2000 ext:5000
}

Received: 3 April 2014 / Accepted: 17 May 2014 / Published: 26 May 2014

\begin{abstract}
Polypropylene composites with different filler contents were prepared by creating a masterbatch containing 3\% wt. filler. A variety of silanol groups were used to synthetized three compounds in different media trough a sol-gel process with acetic acid, formic acid and ammonium hydroxide as catalysts. Besides, three different nanotubular structures were also used to analyze their behavior and compare it with the effect caused by the silanol groups. These tubular structures comprise: unmodified halloysite, carbon nanotubes and functionalized carbon nanotubes. Morphological characterization in SEM and STEM/TEM showed dispersion in the polypropylene matrix. According to TGA measurements, polypropylene filled with functionalized carbon nanotubes is the composite exhibiting better thermal properties. DSC measurements show the presence of two main peaks for temperatures of melting and crystallization which remain similar for all the composites. Mechanical test in tension demonstrate that modulus of the composites increases for all samples with a major impact for materials containing silanol groups synthetized in formic acid. The oxygen transmission rate increased for all samples with exception of samples containing halloysite. Finally, rheological measurements show a significantly increment in viscosity for samples containing unmodified and modified carbon nanotubes. No difference was found for samples containing silanol groups and halloysite when compared to neat polypropylene.
\end{abstract}


Keywords: Organosilanes; silanol; halloysite nanotubes; carbon nanotubes; polypropylene; sol-gel process

\section{Introduction}

The incorporation of inorganic particulate fillers has been proved to be an effective way for the improvement and enhancement in properties, and in particular the toughness and thermal, of polymeric materials [5]. Polypropylene (PP) filled with particulate fillers has been widely studied and presently the research of this polymeric matrix is still increasing. The versatility of PP and its good processability characteristics have also made it favorable for research and development [3].That means a composite with improved properties and lower particle concentration is highly desired. As it was mentioned in a previous work [1] two of the most important characteristics to produce a composite with good properties remain in the ability of the polymeric matrix and the particle to have enough interfacial adhesion as well as in achieving an homogeneous dispersion of the particles within the matrix; this statement is proved and supported for most of the literature already published $[2,3,4]$. However, good dispersion of filler remains the biggest challenge for researchers because of the tendency that particles have to form agglomerates. Consequently, the so-called nanoparticle filled polymers contain a number of clusters of particles and may therefore exhibit properties even worse than conventional particle/polymer systems. It has been documented that the typical filler contents for succeeding a good enhancement of performance is as high as $20 \%$ by volume $[5,6]$; however when more nanoparticles are added, the tensile yield strength becomes lower due to an increased probability of breaking and splitting of the agglomerated nanoparticles [7,8]. Also, such kinds of nanocomposites do not resist crack propagation under higher speed load as effectively as matrix resins, thus exhibiting reduced impact strength values [9]. Based on these results, it can be inferred that it might be impossible to pursue a nano-scale dispersion of the particles, especially when considering the high viscosity of the polymer melt as well as the poor interaction between the hydrophilic fillers and the hydrophobic matrix. Besides the dispersion status promotion, a lot of emphasis should be focused on the modification of the agglomerates themselves by means of a special surface treatment of the nanoparticles as stated by Rong et al.[10].

In this paper, a combination of in-situ polymerization and melt-compounding is developed to overcome the challenges that most of the researchers experience. In the first stage sol-gel process is used to obtain organosilanes where polymers can be kinetically trapped within inorganic matrices under the right set of conditions prior to significant phase separation. The second stage comprises the mechanical mixing of synthetized silanols and nanotubular structures with the polymer to compare the different materials obtained and how properties changed depending on the filler added. The purpose of this paper is to show how efficiently the mechanical, morphological, barrier and thermal properties can be improved by the approach described. PP was chosen as the matrix and three organosilanes were synthetized as fillers to compare their effect against three different nanotubular structures: unmodified halloysite (HNT), carbon nanotubes (CNT) and functionalized carbon nanotubes (CNTF). 


\section{Experimental Section}

\subsection{Materials}

As matrix, a clarified random copolymer of polypropylene (PP) Extrusion-Blown grade was used. This thermoplastic satisfies FDA requirements according the specifications mentioned in $21 \mathrm{CFR}$ 177.1520 (Pro-fax SL262MW, by Indelpro S.A de C.V) with a melt flow index of $1.8 \mathrm{dg} / \mathrm{min}$ and a density of $0.9 \mathrm{~g} / \mathrm{cm}^{3}$. Several approaches were developed in order to test the effect of the HNT, the CNT untreated and treated and the three different products synthetized containing organosilane molecules.

\subsection{Synthesis of organosilanes}

Trimethoxy(propy)silane (TMOPS, 97\%) was purchased from Sigma Aldrich and used without further purification. Distillated water and propyl alcohol were used for the preparation of solutions. Acetic acid, formic acid and ammonium hydroxide are the three different environments were reactions were carried out respectively.

Three different organosilanes samples were obtained by silica-gel process. $20 \mathrm{ml}$ of isopropyl alcohol and $250 \mathrm{ml}$ of distillated water were placed in a glass container with the reagents, $50 \mathrm{ml}$ of TMOPS and $12.5 \mathrm{ml}$ of the different media as shown in Table 1 . The mixture was stirred at low velocity and 50 ${ }^{\circ} \mathrm{C}$ for 2 hours. After completion of reactions a settling time of 48 hours was fixed for the diluent to evaporate and phase separation was observed. Decantation and distillated water washing steps were followed afterwards; finally, another 48 hours of resting time was necessary to let the rest of solvent and water evaporate.

Table 1. Concentrations used for the synthesis of organosilanes samples trough sol-gel process.

\begin{tabular}{|c|c|c|c|}
\hline $\begin{array}{c}\text { Reaction Media } \\
(12.5 \mathrm{ml})\end{array}$ & $\begin{array}{c}\text { Distillated Water } \\
(\mathrm{ml})\end{array}$ & $\begin{array}{c}\text { Isopropyl } \\
\text { alcohol (ml) }\end{array}$ & $\begin{array}{c}\text { TMOPS } \\
(\mathrm{ml})\end{array}$ \\
\hline Acetic acid - $(\mathrm{C} 2 \mathrm{H} 4 \mathrm{O} 2)$ & \multirow{3}{*}{250} & \multirow{3}{*}{20} & \multirow{3}{*}{50} \\
\hline Formic acid $\quad(\mathrm{C} 3 \mathrm{H} 4 \mathrm{O} 3)$ & & & \\
\hline $\begin{array}{l}\text { Ammonium hydroxide } \\
(\mathrm{NH} 4 \mathrm{OH})\end{array}$ & & & \\
\hline
\end{tabular}

\subsection{Nanotubes}

Three different nanotubular structures were used for this research. The first is Halloysite (Kaolin clay) purchased from Sigma Aldrich with dimensions ( $\mathrm{d}$ x L) 30-70 nm x 1-3 $\mu \mathrm{m}$, surface area of $64 \mathrm{~m}^{2} / \mathrm{g}$ and density of $2.53 \mathrm{~g} / \mathrm{cm}^{3}$. The second and third nanotubes were untreated and treated carbon nanotubes all of them multiwall carbon nanotubes (MWCNTs) (CM-95), purchased from Aldrich, prepared by a chemical vapor deposition method. The range in diameter was 6-13 nm; the length of the tubes was $5 \mu \mathrm{m}$; and the purity was greater than $95 \%$. Functionalization of the treated carbon 
nanotubes is fully described by Sánchez-Fernández in a previous work already published [11]. Thriethoxy(octyl)silane with a purity of 97.5\% (Aldrich) and 3-glycidoxypropyltrimethoxysilane with a purity of $98 \%$ (Aldrich) were used as the silane functionalization agents. The reagents used for the acid treatment were nitric acid (70\%, Aldrich), sulfuric acid (95-98\%, Aldrich), acetone (99.5\%, Aldrich), and ethanol (99.5\%, Aldrich).

\subsection{Sample preparation}

PP composites based on silanol, halloysite nanotubes and carbon nanotubes were fabricated via melt mixing using a 3 head mixer (ATR Plati-Corder BRABENDER ${ }^{\circledR}$ ) at $190^{\circ} \mathrm{C}$ with a speed of $10 \mathrm{rpm}$ for $5 \mathrm{~min}$ set as feeding time and $50 \mathrm{rpm}$ during $15 \mathrm{~min}$. These conditions were selected from an optimization process already developed by Bonilla et. al [12] were these conditions resulted as the best to process PP matrix.

The mass fraction of filler within the polymeric matrix was kept constant at $3 \% \mathrm{wt}$. and no other additive was used in the preparation of samples. The prepared materials were press-compressed at $190^{\circ} \mathrm{C}$ and at $15 \mathrm{MPa}$ for $5 \mathrm{~min}$ followed by cooling at room temperature. Finally, samples were shaped into the desired size for further measurements. Code names for each composite/blend are listed in Table 2.

Table 2. Code name for sample prepared in a 3- head mixer.

\begin{tabular}{|l|l|l|}
\hline MATRIX & FILLER & CODE NAME \\
\hline PP- SL262MW & - & PP \\
\hline PP- SL262MW & POSS (acetic acid media) & PP-Acetic \\
\hline PP- SL262MW & POSS (formic acid media) & PP-Formic \\
\hline PP- SL262MW & POSS (ammonium hydroxide media) & PP-Base \\
\hline PP- SL262MW & HNT & PP-HNT \\
\hline PP- SL262MW & Untreated CNT & PP-CNT \\
\hline PP- SL262MW & Functionalized CNT & PP-CNTF \\
\hline
\end{tabular}

\subsection{Thermal analysis}

The measurements were carried out in a thermogravimetric-analyzer (TGA) coupled with DSC from TA Instruments (STD Q600) to identify any changes in the thermal properties, crystallization phenomenon as well as degradation of the sample due to filler presence. This was achieved by measuring the temperature and the difference of temperature of the sample and a thermally inert reference during simultaneous heating or cooling under identical conditions. Procedure included a heat-cool-reheat cycle from $10^{\circ} \mathrm{C}$ to $800^{\circ} \mathrm{C}$ with a temperature rate of $10^{\circ} \mathrm{C} / \mathrm{min}$. The first heating cycle serves to remove previous thermal history from the sample.

Sample was calibrated with Indium metal according to procedure ASTM E794 "Melting Crystallization Temperatures by Thermal Analysis". 


\subsection{Rheological testing}

Frequency sweeps were included in order to characterize the rheological behavior of samples with different fillers in PP matrix. The preparation of samples for the rheological measurements was performed through press compression $\left(25\right.$ tons at $190^{\circ} \mathrm{C}$, for $5 \mathrm{~min}$.) in a CARVER 4122 heating press and round samples with a diameter of $25 \mathrm{~mm}$ and a width of $1 \mathrm{~mm}$ were obtained ..

\subsubsection{Frequency Sweeps}

In rotational methods the test fluid is continuously sheared between two surfaces, one or both of which are rotating. These devices have the advantage of being able to shear the sample for an unlimited period of time under controlled rheometric conditions, incorporating oscillatory or normal stress tests. An Anton Paar Physica MCR301 rheometer was used to run frequency sweeps from 1000 to 0.01 $\mathrm{rad} \cdot \mathrm{s}-1.10 \%$ strain and temperatures of $170^{\circ}, 180^{\circ}$ and $190^{\circ} \mathrm{C}$ were included in the set parameters. Configuration was selected as $25 \mathrm{~mm}$ parallel plate geometry and $1 \mathrm{~mm}$ gap. Data obtained at different temperatures was brought into a single master curve according to Okamoto et al [13].

\subsection{Morphological characterization}

Sample cutting was carried out in an ultra-microtome Powertome XL (RMC). A glass knife was used for the thick a face cut and afterwards the cutting in the next section to obtain a smoothed surface a diamond knife was used. The sections were floated in de-ionized water to select and place them in copper grids supports.

\subsubsection{SEM}

In order to observe the particles dispersion in the different prepared materials, SEM images were taken using a microscope SEM-FEI Nova NanoSEM 200 with an acceleration voltage of $12 \mathrm{kV}$ and a low vacuum detector. The EDS elemental analysis was carried out with an INCA-X-sight. The samples analyzed by SEM include those with nanotubular fillers (PP-HNT, PP-CNT and PP-CNTF) and neat PP for comparison.

\subsubsection{TEM}

TEM analysis was performed in a JEOL model JEM-2200FS +Cs microscope with an acceleration voltage of $200 \mathrm{kV}$. Different micrographies were taken at diverse magnifications in scanning mode (STEM), transmission (TEM), electron diffraction patterns (PD) and elemental analysis (EDS). The samples analyzed by STEM/TEM include those with organosilane filler: PP-Acetic, PP-Formic and PP-Base.

\subsection{Gas barrier testing}

Oxygen permeability of the films was measured according to ASTM D3985 using a MOCON OXTRAN ${ }^{\circledR} 2 / 21$ gas permeation instrument based on the nanometric testing principle. In the nanometric 
testing method, a pressure difference (driving force) across the sample is created by maintaining the test gas at atmospheric pressure in the upper chamber, while vacuum is applied in the lower measuring chamber. While the gas permeates through the sample, the pressure in the lower measuring chamber increases. The instrument measures the time required for the lower chamber pressure to increase from a predefined lower limit to a pre-defined upper limit. The measured time interval is then transformed into the gas permeability rate expressed in $\mathrm{ml} / \mathrm{m}^{2} /$ day. Gas permeability of the films was determined at constant temperature $\left(23^{\circ} \mathrm{C}\right)$ and relative humidity $(0 \% \mathrm{RH})$ conditions with $5-10 \mathrm{~cm}^{3} / \mathrm{min}$ gas flow. Permeability tests were carried out in polygonal specimens of $100 \mathrm{~cm}^{2}$ with an approximate thickness of $1 \mathrm{~mm}$. Values reported represent average of three measurements.

\subsection{Tensile Testing}

To compare mechanical properties of samples, tests were performed in an INSTRON 3365 tensile test machine at a strain rate of $6 \mathrm{~mm} / \mathrm{min}$ in accordance to ASTM 882. Tensile properties were measured on 27 rectangular specimens with a length of $10 \mathrm{~mm}$, a width of $5 \mathrm{~mm}$ and a thickness of $1 \mathrm{~mm}$. Values reported represent average from 5 measurements and typical stress-strain curves were selected for presentation in the graphs.

\section{Results and Discussion}

\subsection{Molecular weight distribution analysis (MWD)}

The molecular weight and structure of a polymer influences the processing behavior and the physical properties of the finished product are essential for good material or product performance. Some properties that are dependent on the molecular weight are the melt viscosity, the tensile strength, toughness or impact strength, thermal resistance and corrosive properties.

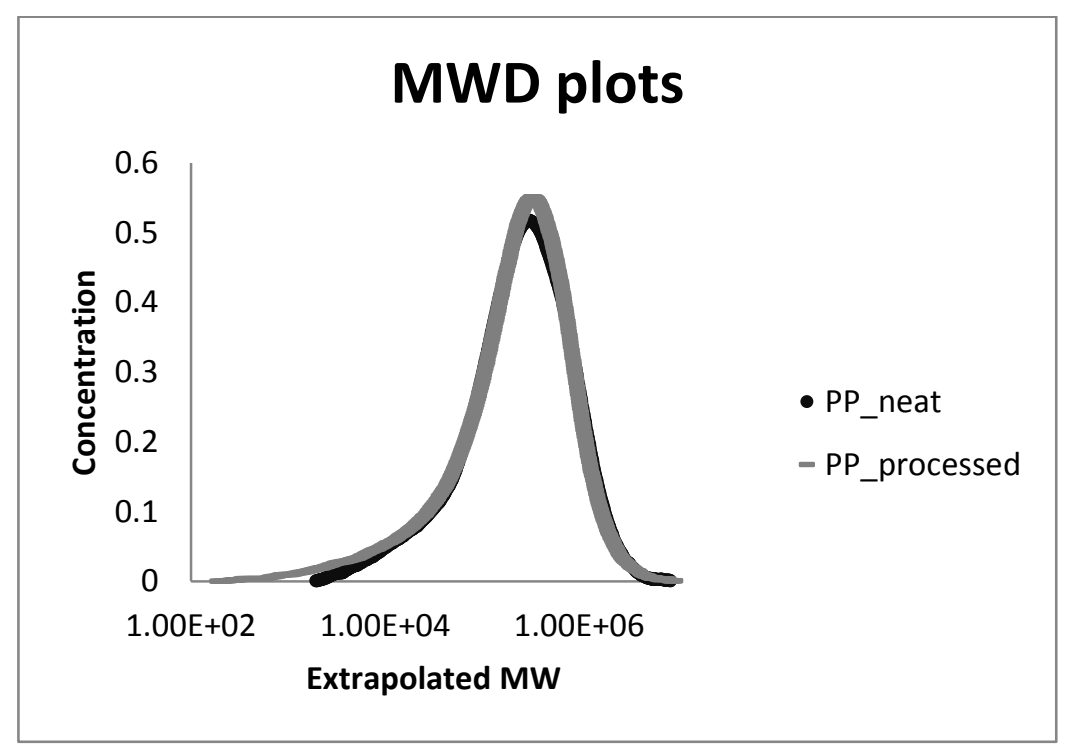

Figure 1.Molecular weight distribution curves as obtained from GPC measurements for the PP resins.

Table 3 presents the moments and polydispersity indices of the molecular weight distribution parameters for all the resins. The objective of this comparison is to ensure consistency so any change 
in the molecular weight distribution of the processed PP when compared to the original PP (as received) exists. If the average molecular weight in number $\left(\mathrm{M}_{\mathrm{n}}\right)$ is considered, the expected behavior of both polymers should be similar. Most thermodynamic measurements are based on the number of molecules and hence depend on $\mathrm{M}_{\mathrm{n}}$ (e.g. colligative properties). The same tendency is observed for the average molecular weight in weight $\left(\mathrm{M}_{\mathrm{w}}\right)$ and the third and fourth moments as well. They present a percentage difference of $2 \%, 9 \%$ and $2 \%$ respectively. With this simple analysis it can be proved that received PP is not affected when it is processed and it will not impact at all in the further results obtained. Small differences in molecular weight between the PP as received and the PP processed could be attributed to a structural changes but we consider this change as non-significant.

Table 3. Moments of the MWD and polydispersity indices for the PP resins before and after processing.

\begin{tabular}{|l|l|l|l|l|l|}
\hline Sample & Mn & Mw & Mz & Mz+1 & PDI \\
\hline PP_neat & 85,776 & 449,894 & $1,116,141$ & $2,127,264$ & 5.25 \\
\hline PP_processed & 75,408 & 460,610 & $1,013,190$ & $2,084,280$ & 6.11 \\
\hline
\end{tabular}

\subsection{Thermal analysis}

TGA curves for the samples in nitrogen are shown in Figure 2 and the characteristic weight loss temperatures are summarized in Table 4 . The most notorious change in weight loss is presented in the range of $440-460^{\circ} \mathrm{C}$ although significant loss in mass starts appearing around $400^{\circ} \mathrm{C}$. The first range of temperature reveals that PP-CNT followed for PP-Formic are the two samples that start degradating EARLY?FIRST?. In the second and third stage it can be observed that the weight-loss percentage remain similar for almost all samples but contrary to the first stage there is a decrease in the degradation rate of samples containing CNT. The last two stages confirm that the lower degradation rate belongs to samples containing CNT (untreated and functionalized), followed by samples containing silanols and resulting the worst performance for samples containing HNT. PP-CNT and PPCNTF have their higher losses in the range of 460 to $550^{\circ} \mathrm{C}$, as expected.

Previous investigations [1] suggested that the barrier properties of the nanoscale fillers were responsible for the enhancement of thermal stability of nanocomposites. It is appreciated in the range of 420 to $460^{\circ} \mathrm{C}$ that the degradation rate of samples when compared with pure PP was impacted positively. Gilman $[14,15]$ believes that the barrier properties could include both the thermal barrier, which protects the polymer from contacting with fire, and the mass transport barrier, which slows down the escape of the volatile products during the process of degradation.

Table 4. Weight loss divided in temperature ranges where changes in weight derivate were observed. 


\begin{tabular}{|c|c|c|c|c|c|}
\hline \multirow{2}{*}{ Sample } & \multicolumn{5}{|c|}{ Weight Loss [\%] } \\
\hline & $175-325^{\circ} \mathrm{C}$ & $400-420^{\circ} \mathrm{C}$ & $420-440^{\circ} \mathrm{C}$ & $440-460^{\circ} \mathrm{C}$ & $460-550^{\circ} \mathrm{C}$ \\
\hline PP & 0.07 & 5.13 & 15.35 & 53.30 & 22.78 \\
\hline PP-Acetic & 0.00 & 5.24 & 13.52 & 41.42 & 32.05 \\
\hline PP-Formic & 0.27 & 4.84 & 13.61 & 43.99 & 28.39 \\
\hline PP-Base & 0.14 & 5.06 & 15.29 & 40.90 & 32.23 \\
\hline PP-HNT & 0.15 & 3.49 & 14.70 & 67.22 & 12.57 \\
\hline PP-CNT & 0.56 & 0.96 & 6.96 & 39.84 & 45.04 \\
\hline PP-CNTF & 0.04 & 0.39 & 3.85 & 35.61 & 59.63 \\
\hline
\end{tabular}

Therefore it could be concluded that the barrier effects of HNTs is not the leading factor in determining the thermal stability of PP/HNTs nanocomposites. Some other investigations indicate that the iron oxides in the silicate fillers and carbon nanotubes could act as flame retardant additives and lead to some radical trapping during the process of degradation, thus enhancing the thermal stability of nanocomposites $[16,17]$.

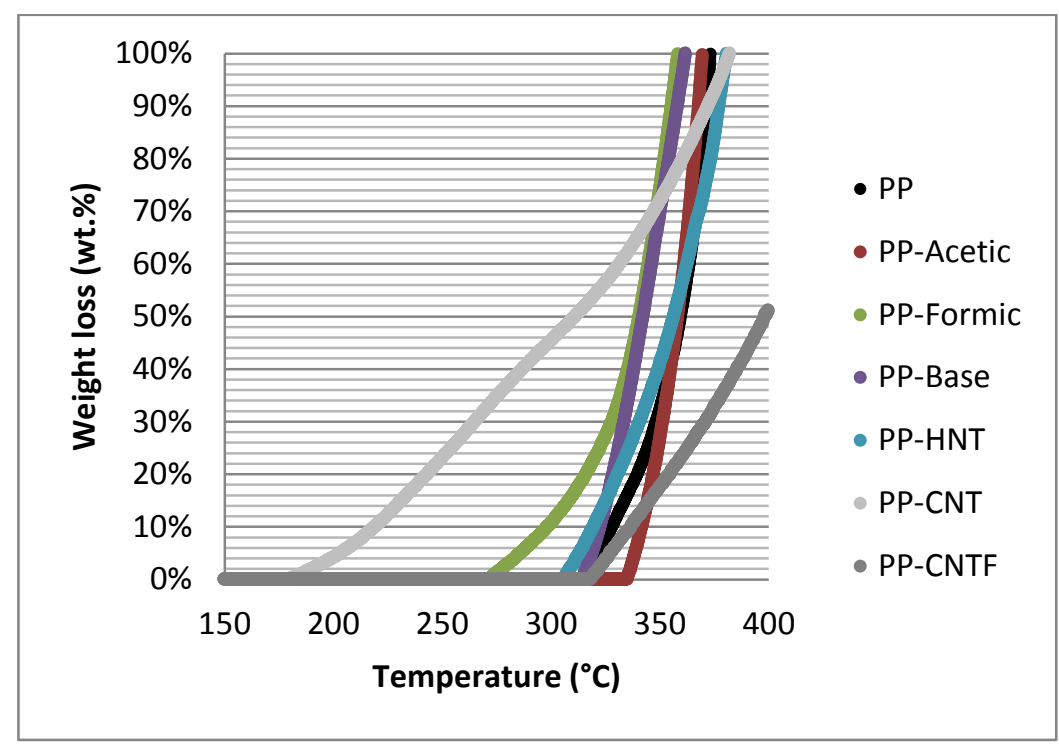

Figure 2. Temperature range where samples start the weight loss (degradation starts).

Table 5 summarizes the results presented in Figure 3. The 1st peak can be attributed to the melting temperature of samples. No significant change is observed comparing the melting temperatures with respect to the pure PP. The appearance of a second peak around $450^{\circ} \mathrm{C}$ could be the result of a crystallization of the samples where molecules tendency is to reorganize themselves. The presence of this peak occurs at a temperature higher than the pure PP. This result can be attributed to the effect of the filler added to the samples, where these particles are acting as nucleate centers to promote crystallization [1]. It is interesting to investigate the effect of fillers with a high aspect ratio on the crystalline behavior of PP it being a semi-crystalline polymer. Its main, stable crystal form is the (monoclinic) form. The orientation of crystallites under stress or in the presence of some filler with a 
high aspect ratio, such as magnesium hydroxide or talc, can occur. It is believed that the orientation of crystallites can improve the mechanical properties.

Table 5.Temperatures where first and second peak appear in DSC referring to melting and crystallization temperatures respectively.

\begin{tabular}{|l|c|c|}
\hline \multicolumn{1}{|c|}{ Sample } & 1st. peak Temperature $\left[{ }^{\circ} \mathbf{C}\right]$ & 2nd. peak Temperature $\left[{ }^{\circ} \mathbf{C}\right]$ \\
\hline PP & 154.55 & 455.91 \\
\hline PP-Acetic & 152.17 & 460.40 \\
\hline PP-Formic & 152.49 & 457.96 \\
\hline PP-Base & 152.56 & 461.39 \\
\hline PP-HNT & 152.92 & 455.47 \\
\hline PP-CNT & 154.16 & 464.59 \\
\hline PP-CNTF & 152.52 & 467.86 \\
\hline
\end{tabular}

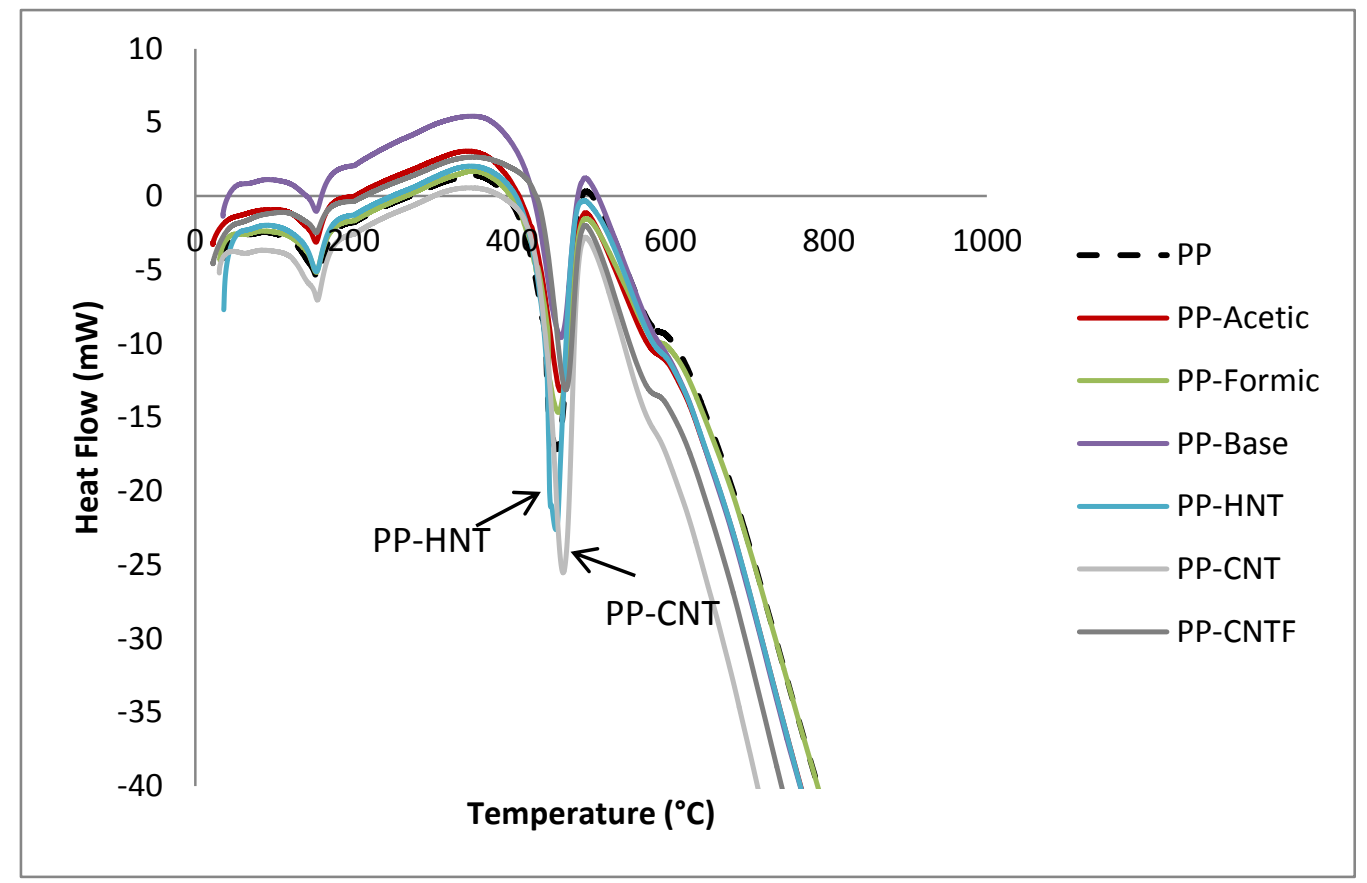

Figure 3.DSC curves extracted from DTA analysis for all samples.

\subsection{Rheological testing}

The rheological properties of PP and its nanocomposites, with HNT, CNT, CNTF and synthetized products are represented in the following figures. Figure 4 shows the viscosity curve of the samples at $190^{\circ} \mathrm{C}$ as a function of the frequency. The results clearly indicate that viscosity of composites containing CNT untreated and modified increased when compared to pure PP. For samples containing synthetized molecules via Sol-gel process a decrease in this property is present as shown in the figure below. 


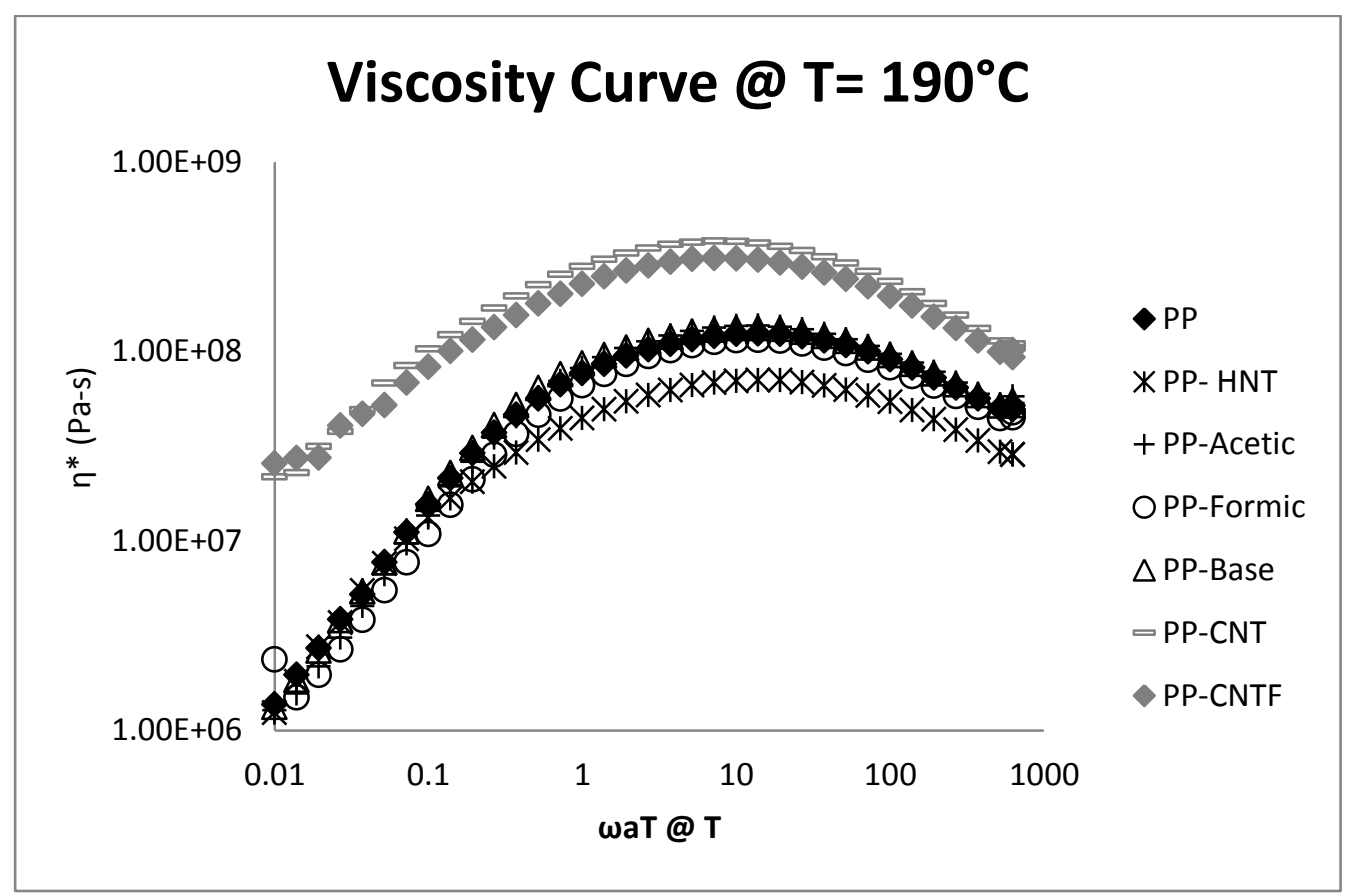

Figure 4. Viscosity curve @ $190{ }^{\circ} \mathrm{C}$ for all samples.

Storage modulus of samples increases as well for samples containing carbon nanotubes, which is due to the reinforcement effect and restrictions in the chain mobility. This behavior is not observed for samples containing HNT which would be expected due to the similar molecular structure. It can be assumed that this behavior could be because of a major compatibility between carbon atoms with the polymeric matrix than silicon in the HNT structure. For PP containing synthetized products the storage modulus do not present any significant change when compared to neat PP. This property resulted increased only for samples containing CNT's this means that the incorporation of CNT into the PP matrix remarkably enhances stiffness and load bearing capability of the material.

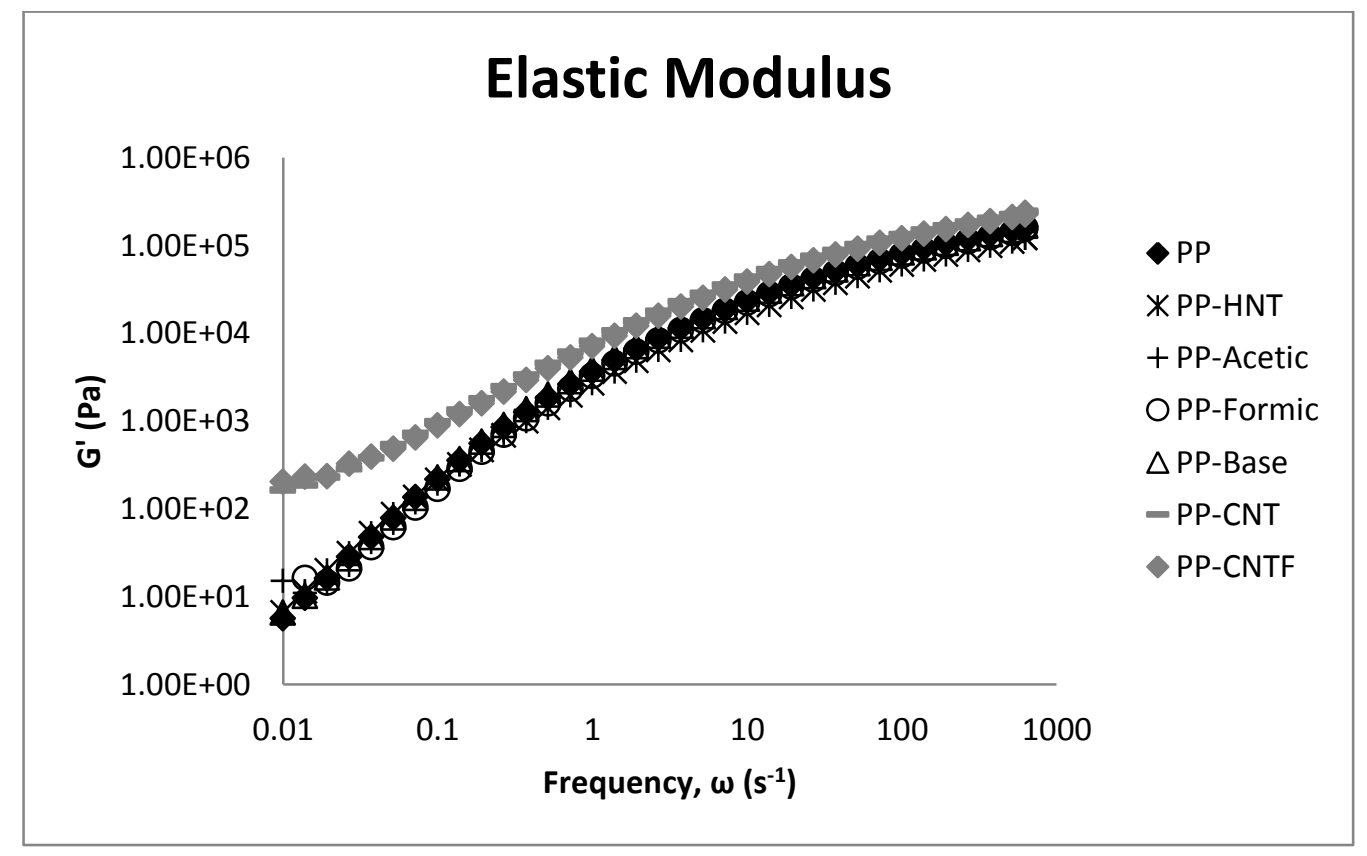

Figure 5. Storage modulus $\left(G^{\prime}\right)$ for all samples. 


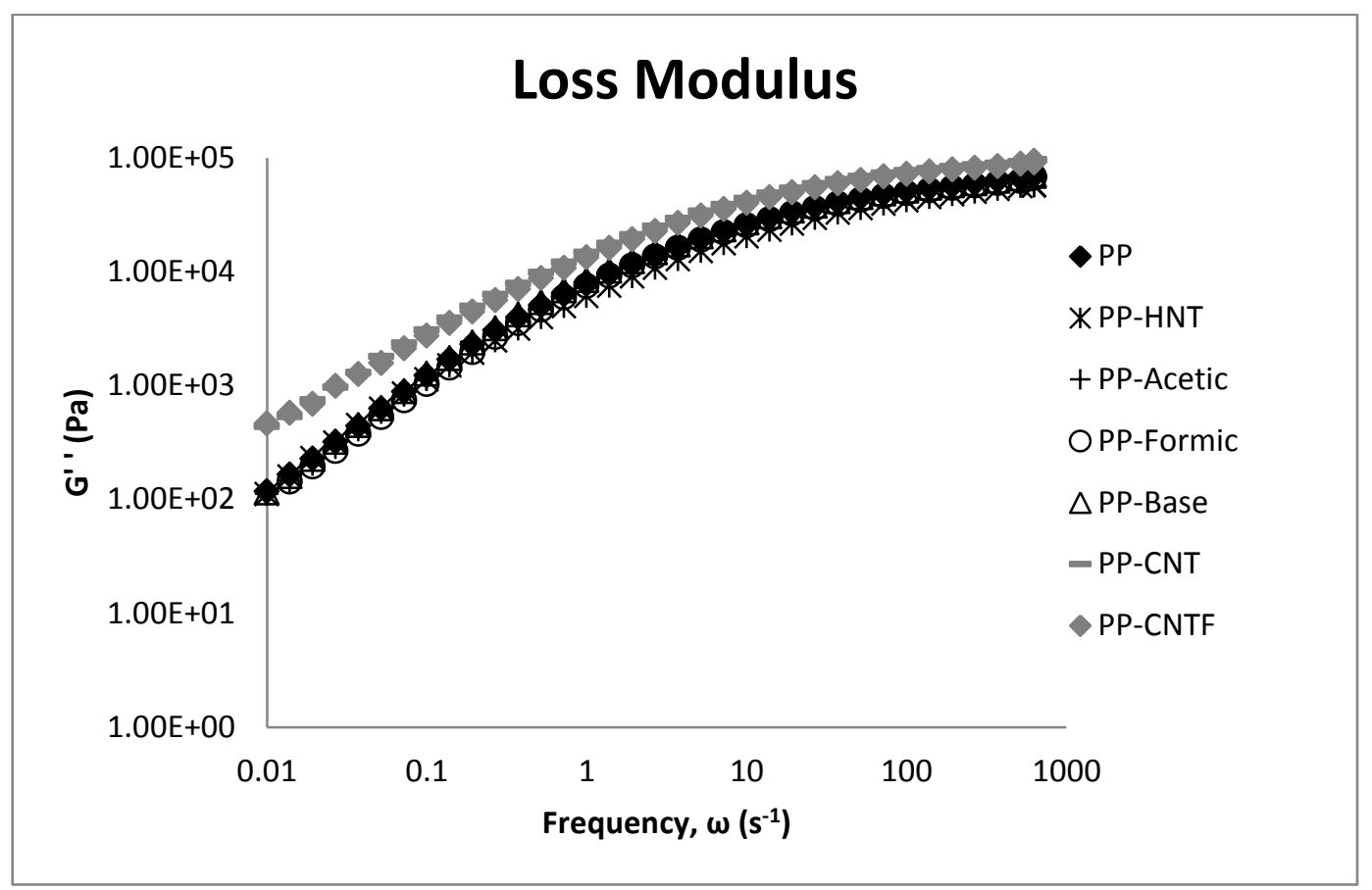

Figure 6. Loss modulus ( $\left.\mathrm{G}^{\prime \prime}\right)$ with frequency sweeps as a function of the filler type.

Figure 7 illustrates the effect of the fillers in the loss factor ( $\tan \delta$ ) for PP composites.

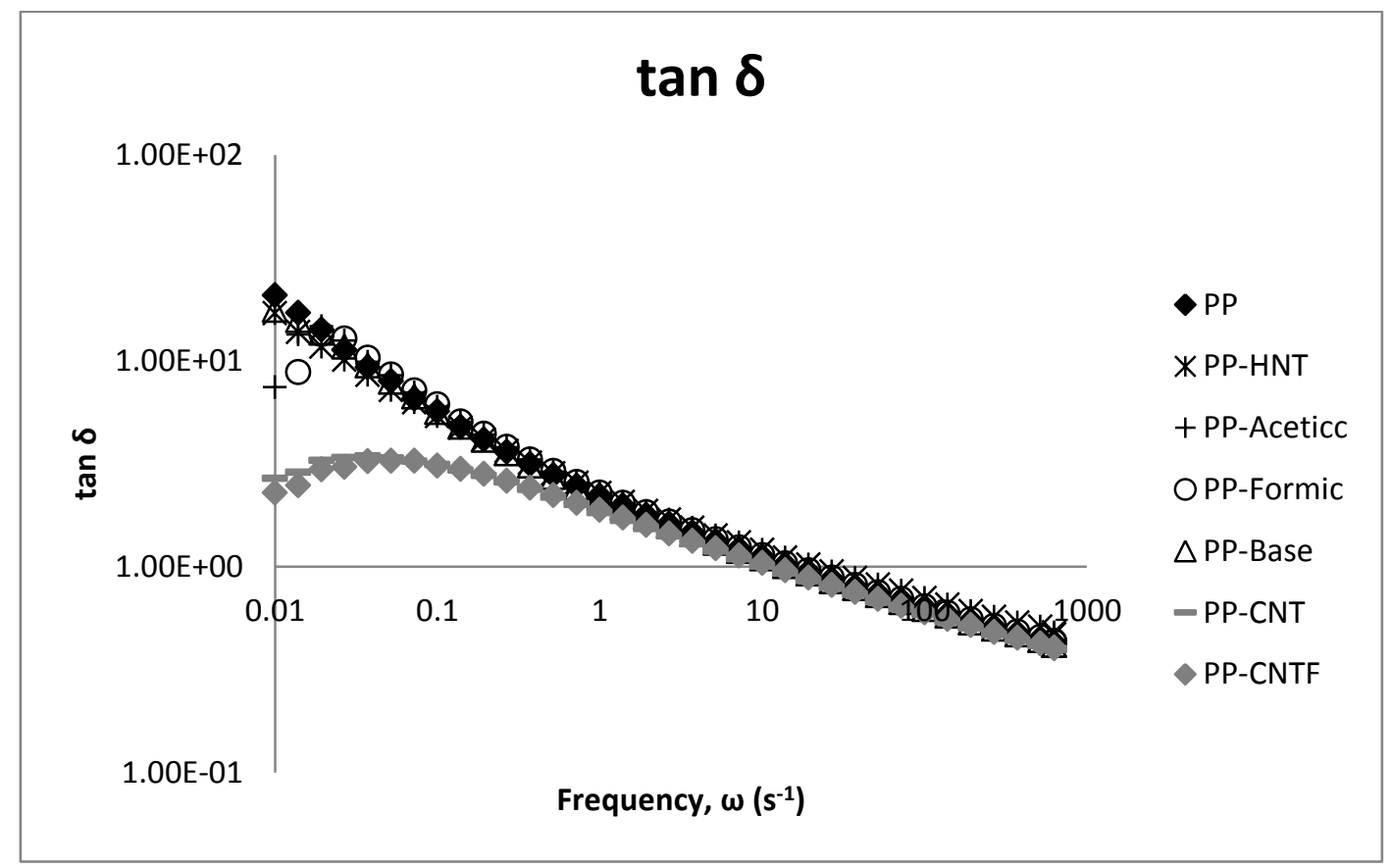

Figure 7. Tan $\delta$ with frequency sweeps as a function of the filler type.

In general, it can be said that the storage and loss modulus behave similar but at low frequencies the changes for CNT's composites when compared to the others samples are better appreciated specially in $\tan \delta$ plot. These analyses show a clear difference between the composites containing CNT which could be attributed to the compatibility between the additive (silanol or filler) and the polymeric matrix, and for these results we can say that the processability of samples containing silanols 
synthetized in any media and samples containing HNT is similar than the processability of neat PP. Contrary for samples containing untreated and functionalized CNT is expected to change.

\subsection{Morphology}

\subsubsection{SEM}

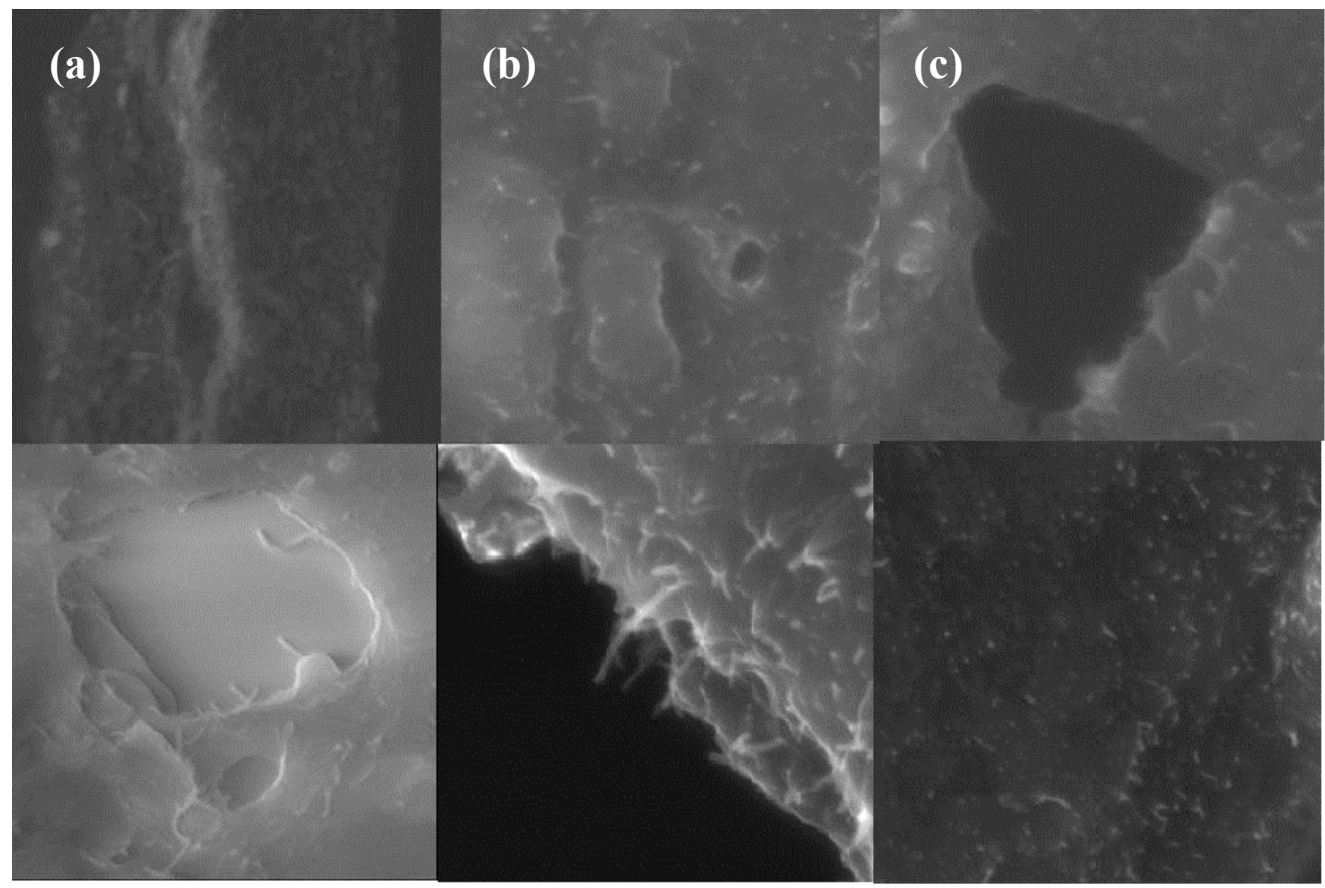

Figure 8. SEM images for samples a) PP-HNT, b) PP-CNT and c) PP-CNTF. Upper images show the morphologies at 100,000X and lower images in immersion mode taken at 200,000x

PP-HNT (Figure 8-a) does not present the same morphology than the samples containing carbon nanotubes, although it contains as well some micrometric agglomerates containing halloysite nanotubes and the fibrous structure of this material was successfully detected by the microscope. The following figure (Figure 8-b) presents the sample containing carbon nanotubes but with no treatment on the surface. This sample presents agglomerates in micrometric scale more or less homogeneously distributed along the analyzed surface. Finally, the polypropylene containing the functionalized carbon nanotubes (PP-CNTF) is presented. In the lower image of Figure 8-a it can be appreciated that low contrasts are presented, this zones were not observed in the neat PP sample. The analysis at higher magnification showed that these zones are agglomerates of carbon nanotubes in micrometric scale. These agglomerates were shown dispersed in all cuts/ slices analyzed.

\subsubsection{STEM/TEM}

The next group of figures was obtained via STEM and they contain a clear field and a Z-contrast where the atomic mass is detected. This analysis is more oriented at the detection of elements present in each sample. 


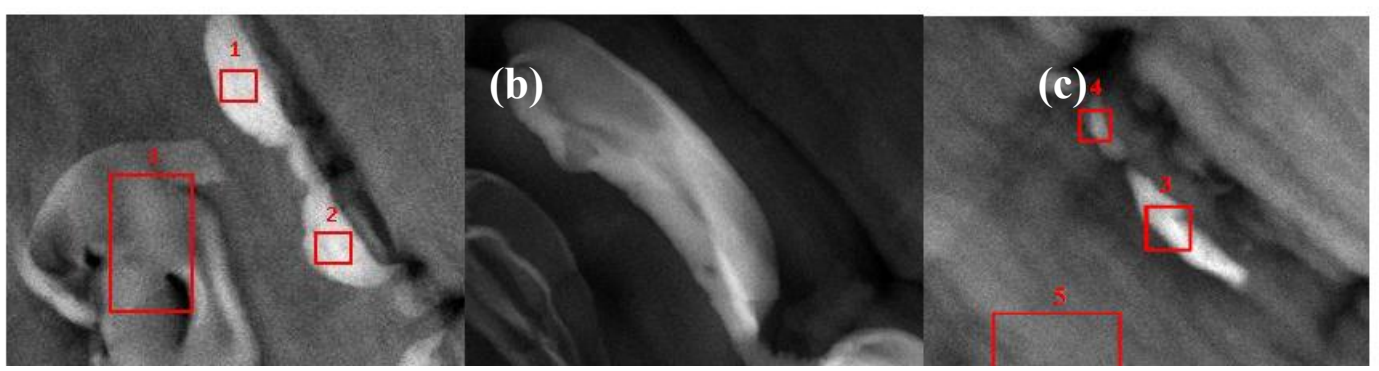

Figure 9. STEM images for a) PP-acetic, b) PP-formic and c) PP-Base samples. Brighter locations show the presence of silicon molecules.

Silicon was detected in the zones analyzed and where only carbon was found refers to the composition of the PP matrix. With this information one can suppose that the formation of agglomerates of the synthetized products in these samples were found. But one important thing on doing this test was to prove the presence of Silicon as the molecular filler assembled to the PP matrix, which impact in properties will be compared to the effect of having tubular filler. In general, it can be said that all the samples presented an intercalated dispersion of filler as supported by the micrographies already described above.

\subsection{Gas barrier properties}

Nanoparticles are well known to reduce the oxygen permeability due to the barrier effect produced by fillers building a tortuous path in polymeric matrices. In the case of PP/MWCNT the studies of gas permeability are limited as well for HNT. For samples containing silanols as fillers literature is even more limited. Because the same behavior was observed in samples of PP containing the synthetized products, oxygen permeability test were carried out just for the samples containing silanols using formic acid as catalyst. Thus, it is believed that their addition in the resin matrix would enhance its barrier properties by forcing the gas molecules to follow a more tortuous path as they diffuse through the material, retarding the progress of the phenomenon. This has been observed in many polymer/layered silicate nanocomposites as well as in iPP using fumed silica nanoparticles [18,19].

Table 6. Oxygen transmission rate of samples.

\begin{tabular}{|l|c|}
\hline Sample & Oxygen Transmission Rate [ce/m2-day] \\
\hline PP & 412.55 \\
\hline PP-HNT & 115.80 \\
\hline PP-Formic & 743.27 \\
\hline PP-CNT & 517.96 \\
\hline PP-CNTF & 10008.23 \\
\hline
\end{tabular}

The presence of fillers in the studied nanocomposites is believed to create a labyrinth, complicating the path that the gas molecules must follow in order to pass through the whole width of the film. It is observed that the oxygen transmission rate did not improve with respect to the pure PP [20]. One 
reason for this behavior is that fillers could form clusters indicating that a good dispersion for these additives was not completely achieved. Although a remarkable improvement is observed for samples containing HNT, where OTR was reduced significantly.

\subsection{Tensile testing}

Table 7 lists the tensile properties of the PP and PP composites. It can be observed that the maximum stress increases for almost all samples excluding for PP containing the silanols obtained in formic acid for which the stress decreased. The maximum stress was achieved for the PP containing silanols synthetized in acetic acid followed by CNTF. The maximum strain was achieved by the same samples. This property increase should be attributed to the changes in crystal structure and orientation of PP induced by the incorporation of the different fillers. As expected, the presence of CNT's untreated and functionalized as well as PP containing a similar structure than CNTs, in this case HNT, improved the Young's modulus. For samples containing silanol groups the higher Young modulus is presented in PP containing organosilanes obtained by sol-gel process using formic acid as catalyst. As mentioned previously, in order to obtain better properties, a better dispersion of the fillers, a reduced number of defects, curvatures and entanglements, and enhanced adhesion between the PP and the filler is required.

Table 7. Mechanical properties of pure PP, PP/silanes and PP/filler composites (3 wt\%)

\begin{tabular}{|l|c|c|c|}
\hline SAMPLE & Max Stress [MPa] & Max Strain [\%] & Young Modulus [MJ/m3] \\
\hline PP & $17.8 \pm 1.4$ & $8.6 \pm 0.8$ & $4.1 \pm 0.4$ \\
\hline PP-HNT & $18.3 \pm 0.4$ & $6.8 \pm 0.2$ & $5.0 \pm 0.1$ \\
\hline PP-Acetic & $21.3 \pm 0.9$ & $11 \pm 0.4$ & $4.7 \pm 0.2$ \\
\hline PP-Formic & $17.2 \pm 1.0$ & $7.8 \pm 0.6$ & $5.6 \pm 0.3$ \\
\hline PP-Base & $17.8 \pm 3.8$ & $9.2 \pm 2.0$ & $4.0 \pm 0.5$ \\
\hline PP-CNT & $19.0 \pm 0.4$ & $7.8 \pm 0.3$ & $4.5 \pm 0.3$ \\
\hline PP-CNTF & $20.8 \pm 1.1$ & $8.5 \pm 0.1$ & $5.0 \pm 0.1$ \\
\hline
\end{tabular}

\section{Conclusions}

To improve the load transfer in composites between the matrix and filler a covalent linking between the two components is desirable. A study of the effects of three different kinds of filler treatment (acetic acid, formic acid and ammonium hydroxide) has revealed that no difference in properties occurred when comparing the three products synthetized. For all characterization of samples containing PP and organosilanes synthetized in different media the properties behave similar (e.g. rheological, barrier, tensile). So we conclude that there is no impact in the catalyzers used to obtain these products; at the end the effect over the polymeric matrix will result the same. In OTR test the 
sample containing HNT resulted in improving properties when compared to neat PP whereas for other samples this property was not improved. Tensile properties when talking about Young's modulus was improved for major of samples. To increase the compatibility between PP and HNTs, grafting PP chains onto the surface of HNTs is being carried out to increase the mechanical performance of nanocomposites. Halloysite nanotubes are unique nanomaterials. Thus being small in size, HNTs does not show any toxicity even at high concentrations and cytotoxicity will not be an issue in future applications contrary to CNT's. So it can be concluded that HNTs possess promising prospects in the preparation of new structural and functional materials and due to this special efforts in improving properties with this filler are needed.

\section{References and Notes}

1. Monsiváis-Barrón A.J., Bonilla-Rios J., Ramos de Valle L.F., Palacios E. Oxygen permeation properties of HDPE layered silicate nanocomposites, Polym.Bul.2013, Vol. 70, p. 939-951

2. Lozano T., Lafleur P.G., Grmela M. J. A Chemical Model for the Dispersion of Fillers in a Polymeric Matrix, Chem. Eng. 2002, Vol. 80, p. 1135-1142

3. Liu J., Gao Y., Cao D., Zhang L., Guo Z. Nanoparticle dispersion and aggregation in polymer nanocomposites: insight from molecular dynamics simulation, Lang.2011, Vol.27, p 7926-7933

4. Kasaliwal G.R., Göldel A., Pötschke P. Influence of polymer matrix melt viscosity and molecular weight on MWCNT agglomerate dispersion,Polym.2011, Vol. 52, p. 1027-1036

5. Pukanszky B. Particulate filled polypropylene composites. In: Karger- Kocsis J, editor. Polypropylene: an A-Z reference, Dordrecht: Kluwer Academic Publishers, 1999. p. 574-80.

6. Savadori A, Scapin M, Walter R. Macromol Symp 1996, Vol. 108, p. 1-289

7. Li JX, Silverstein M, Hiltner A, Baer E. The ductile-to-quasi brittle transition of particulatefilled thermoplastic polyester. J Appl Polym Sci 1994, Vol.52, p. 255-67.

8. Ess JW, Hornsby PR. Twin-screw extrusion compounding of mineral filled thermoplastics: Dispersive mixing effects. Plast, Rubber Compos Process Appl 1987,Vol. 8, p. 147-56.

9. Wang Y, Huang J.S. Single Screw Extrusion Compounding of Particulate Filled Thermoplastics: State of Dispertion and Its Influence on Impacts Properties. J Appl Polym Sci.1996, Vol.60, p.1779-91.

10. Rong M.Z., Zhang M.Q:, Zheng Y.X:, Zeng H.M:, Walter R., Friedrich K. Structure-property relationship of irradiation grafted nano-inorganic particle filled polypropylene composites, Polym.2001, Vol.42, p. 167-183 
11. Sánchez-Fernández A., Cué Sampedro R., Peña-Parás L., Palacios-Aguilar E. Functionalization of Carbon Nanotubes and Polymer Compatibility Studies, J. Mat Sci. Res.2014, Vol.1, p. 1-12

12. Bonilla-Rios J. Effects of peroxide on molecular weight and rheological properties of polypropylene resins. PhD dissertation. Texas A\&M University,1996.

13. Okamoto M., Sinha-Ray S., Yamada K., Ueda K. New polylactide-layered silicate nanocomposites. 2. Concurrent improvements of material properties, biodegradability and melt rheology, Polym. 2003, Vol.44, p. 857-866

14. Gilman J.W. Flammability and thermal stability studies of polymer layered-silicate (clay) nanocomposites, Appl. Clay Sci. 1999, Vol.15, p.31-49

15. Gilman J.W., Jackson CL, Morgan A.B., Harris R., Manias E., Giannelis E.P. Flammability properties of polymer-layered silicate nanocomposites. Propylene and polystyrene nanocomposites, Chem Mater. 2000, Vol. 12, p. 1886-1883

16. Kashiwagi T., Grulke E., Hilding J., Harris R., Awad W., Douglas J., Thermal Degradation and Flammability Properties of Poly(propylene)/Carbon Nanotube Composites, Macromol Rapid Commun.2002, Vol. 23, p. 761-765

17. Zhu J., Uhl F.M., Morgan A.B., Wilkie C.A. Studies on the mechanism by which the formation of nanocomposites enhance thermal stability, Chem Mater. 2001,Vol. 13, p. 4649-4654

18. Vladimirov, V.; Betchev, C.; Vassiliou, A.; Papageorgiou, G.; Bikiaris, D. Dynamic mechanical and morphological studies of isotactic polypropylene/fumed silica nanocomposites with enhanced gas barrier properties, Comp. Sci. Technol. 2006,Vol.66, p. 2935-2944.

19. Vassiliou, A.; Bikiaris, D.; Pavlidou, E. Macromol. Optimizing melt-processing conditions for the preparation of iPP/fumed silica nanocomposites: Morphology, mechanical and gas permeability propertie React. Eng. 2007, Vol. 1, p. 488-501.

20. Bikiaris D., Microstructure and Properties of Polypropylene/Carbon Nanotube Nanocomposites Mater.2010, Vol.6, p. 2884-2946.

C 2014 by the authors; licensee MDPI, Basel, Switzerland. This article is an open access article distributed under the terms and conditions of the Creative Commons Attribution license (http://creativecommons.org/licenses/by/3.0/). 